\title{
Cronkhite-Canada Syndrome Complicated by Triple Primary Cancers
}

Kohei Yamanouchi, Yasuhisa Sakata, Nanae Tsuruoka, Ryo Shimoda, Masahiko Uchida, Takashi Akutagawa, Shimpei Shirai, Kazuma Fujimoto and Ryuichi Iwakiri

\begin{abstract}
We herein report a case of Cronkhite-Canada syndrome (CCS) complicated with triple primary cancers. The patient was diagnosed with CCS at 65 years of age. At 76 years of age, one of his colon polyps was diagnosed as adenocarcinoma. At 81 years of age, gastric carcinoma was detected. Weight loss and fatigue appeared one month before he visited our hospital. An examination revealed dilatation of the intrahepatic bile duct. Cholangiocarcinoma was diagnosed as a result of bile duct cytology. Patients with CCS should be monitored carefully for carcinoma of systemic organs as well as the gastrointestinal tract.
\end{abstract}

Key words: Cronkhite-Canada syndrome, gastrointestinal carcinoma, cholangiocarcinoma

(Intern Med 55: 1569-1573, 2016)

(DOI: 10.2169/internalmedicine.55.6594)

\section{Introduction}

Cronkhite-Canada syndrome (CCS) is a nonhereditary syndrome characterized by gastrointestinal polyposis, alopecia, hyperpigmentation, onycholysis, and hyponutrition associated with diarrhea. CCS is a rare disease, and only 450 cases have been described in the literature thus far since Cronkhite and Canada first reported two cases in 1955 (1,2). Approximately two-thirds of patients are of Japanese descent (3). Previously, gastrointestinal polyps of CCS were not considered to be a high risk for malignant disease. However, the number of cases of CCS complicated with gastrointestinal cancer has increased (4-6). We herein report a patient with CCS complicated with cholangiocarcinoma who was previously diagnosed with gastric cancer and colon cancer treated with surgery.

\section{Case Report}

The patient was an 82-year-old Japanese man. He was diagnosed with CCS at 65 years of age and suffered from alopecia, hyperpigmentation, diarrhea, and gastrointestinal polyposis (Fig. 1). He received long-term treatment with oral prednisolone to stabilize the symptoms. At 76 years of age, multiple colon polyps were detected by screening colonoscopy, and endoscopic mucosal resection (EMR) was performed. The pathological diagnosis confirmed that the sigmoid colon polyp was well-differentiated tubular adenocarcinoma. The cancer invaded sm2, and additional surgery was performed after EMR. Pathological Stage I (sm, NO, M0) was diagnosed after surgery. At 81 years of age, an ulcerative lesion was detected by screening esophagogastroduodenoscopy in the pyloric region of the stomach. A biopsy revealed poorly differentiated tubular adenocarcinoma of the stomach. Laparoscopy-assisted distal gastrectomy was performed for the gastric cancer. Pathological Stage IIIA (T4a, N1, M0) was diagnosed after surgery. The patient refused postoperative adjuvant chemotherapy.

At 82 years of age, he visited our hospital due to a $10 \mathrm{~kg}$ weight loss and physical fatigue after his last hospital visit approximately 1 month previously. A physical examination revealed jaundice. Laboratory data indicated hyperbilirubinemia, increased serum transaminase, hemoglobin of $12.0 \mathrm{~g} /$ $\mathrm{dL}$, white blood cell count of $7,900 / \mu \mathrm{L}$, blood platelet count of $21 \times 10^{3} / \mu \mathrm{L}, \mathrm{C}$-reactive protein of $3.44 \mathrm{mg} / \mathrm{dL}$, total bilirubin of $6.4 \mathrm{mg} / \mathrm{dL}$, aspartate aminotransferase of $99 \mathrm{U} / \mathrm{L}$, alanine aminotransferase of $116 \mathrm{U} / \mathrm{L}$, alkaline phosphatase of 2,189 U/L, $\gamma$-glutamyl transferase of 1,354 U/L, carcinoembryonic antigen of $1.6 \mathrm{ng} / \mathrm{mL}$ and carbohydrate antigen 

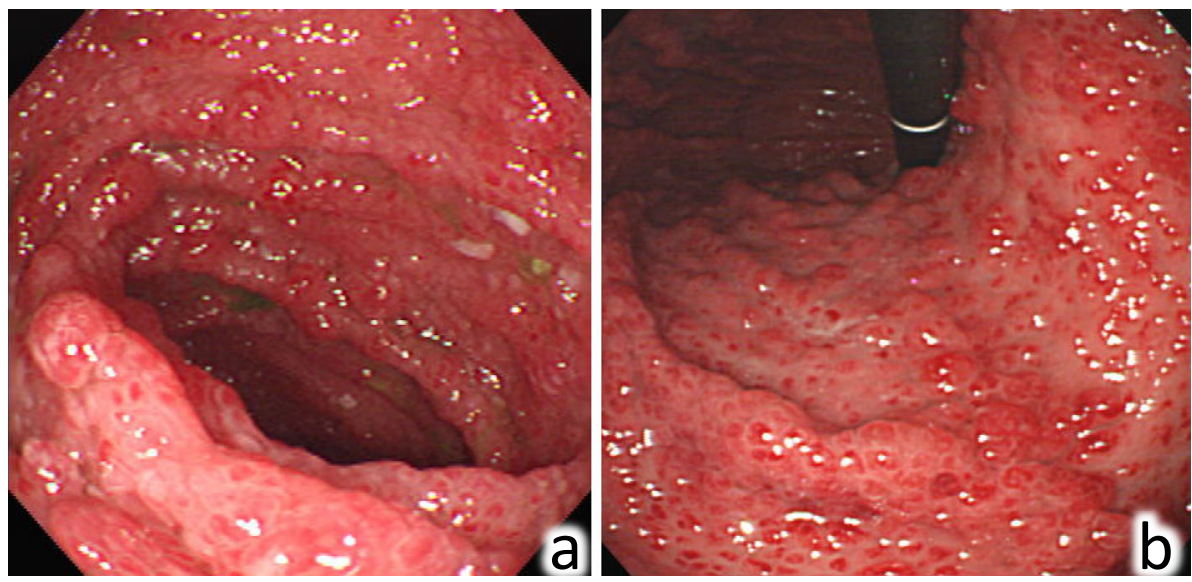

Figure 1. Endoscopic findings of the gastrointestinal tract at the initial diagnosis. a: The colon revealed mucosal edema and diffuse polyposis. b: Endoscopic findings of the stomach revealed multiple polyposis.

Table. Laboratory Data on Admission.

\begin{tabular}{|c|c|c|c|c|c|c|c|}
\hline & & Unit & Reference range & & & Unit & Reference range \\
\hline \multicolumn{8}{|c|}{ CBC } \\
\hline WBC & 6200 & $/ \mu \mathrm{L}$ & $3900-9800$ & AST & 67 & $\mathrm{U} / \mathrm{L}$ & $10-35$ \\
\hline $\mathrm{RBC}$ & 3.62 & $\times 10^{4} / \mu \mathrm{L}$ & $4.10-5.30$ & ALT & 66 & $\mathrm{U} / \mathrm{L}$ & $5-40$ \\
\hline $\mathrm{Hb}$ & 11.0 & $\mathrm{~g} / \mathrm{dL}$ & $13.5-17.6$ & LDH & 203 & $\mathrm{U} / \mathrm{L}$ & $120-230$ \\
\hline Plt & 18.5 & $\times 10^{4} / \mu \mathrm{L}$ & $13.1-36.2$ & ALP & 1889 & $\mathrm{U} / \mathrm{L}$ & $110-360$ \\
\hline \multicolumn{2}{|c|}{ Coagulation } & & & $\gamma$-GTP & 1553 & $\mathrm{U} / \mathrm{L}$ & $10-50$ \\
\hline PT & 77.0 & $\%$ & $70.0-130.0$ & AMY & 56 & $\mathrm{U} / \mathrm{L}$ & $40-130$ \\
\hline PT-INR & 1.13 & & $0.90-1.10$ & CRP & 3.03 & $\mathrm{U} / \mathrm{L}$ & $0.00-0.30$ \\
\hline APTT & 111.1 & $\%$ & & \multicolumn{2}{|c|}{ Tumor marker } & & \\
\hline \multicolumn{2}{|c|}{ Biochemistry } & & & CEA & 1.6 & $\mathrm{ng} / \mathrm{dL}$ & $0.0-5.0$ \\
\hline $\mathrm{TP}$ & 6.2 & $g / d L$ & $6.7-8.3$ & CA19-9 & 32 & $\mathrm{U} / \mathrm{mL}$ & $0-37$ \\
\hline $\mathrm{Alb}$ & 2.9 & $\mathrm{~g} / \mathrm{dL}$ & $3.8-5.0$ & DUPAN2 & 204 & $\mathrm{U} / \mathrm{mL}$ & $0-150$ \\
\hline BUN & 12.8 & $\mathrm{mg} / \mathrm{dL}$ & $8.0-20.0$ & SPan-1 & 89 & $\mathrm{U} / \mathrm{mL}$ & $0.0-30.0$ \\
\hline $\mathrm{Cr}$ & 0.93 & $\mathrm{mg} / \mathrm{dL}$ & $0.60-1.10$ & \multicolumn{2}{|c|}{ Viral marker } & & \\
\hline T-bil & 8.5 & $\mathrm{mg} / \mathrm{dL}$ & $0.2-1.0$ & HBs-Ag & 0.01 & $\mathrm{U} / \mathrm{mL}$ & $0.00-0.04$ \\
\hline D-bil & 4.9 & $\mathrm{mg} / \mathrm{dL}$ & $0.0-0.3$ & HCV-Ab & 0.07 & $\mathrm{~S} / \mathrm{CO}$ & $0.00-0.99$ \\
\hline Glu & 211 & $\mathrm{mg} / \mathrm{dL}$ & $70-110$ & & & & \\
\hline
\end{tabular}

TP: total protein, Alb: albumin, BUN: blood urea nitrogen, Cr: creatinine, T-bil: total bilirubin, D-bil: direct bilirubin, AST: aspartate aminotransferase, ALT: alanine aminotransferase, LDH: lactate dehydrogenase, ALP: alkaline phosphatase, $\gamma$-GTP: gamma-glutamyl transferase, AMY: amylase, CRP: C-reactive protein, CEA: carcinoembryonic antigen, CA19-9: carbohydrate antigen 19-9, DUPAN2: pancreatic cancer-associated antigen-2, Span-1: S-pancreas-1 antigen, HBS-Ag: hepatitis B surface antigen, $\mathrm{HCV}-\mathrm{Ab}$ : anti-hepatitis $\mathrm{C}$ virus antibody

19-9 of $32 \mathrm{U} / \mathrm{mL}$ (Table). Contrast abdominal computed tomography (CT) showed dilatation of the intrahepatic bile duct. In addition, bile duct wall thickening and tumor formation were observed in the middle bile duct (Fig. 2a, b). A tumor measuring $22 \mathrm{~mm}$ with contrast effect in the arterial phase was detected in S7 of the liver (Fig. 2c). Cholangiocarcinoma was suspected according to the CT findings, and endoscopic retrograde cholangiography was initially attempted. However, cannulation of the duodenal papilla was unsuccessful due to previous Roux-en-Y anastomosis. At a later date, percutaneous transhepatic cholangiodrainage (PTCD) was performed to place a plastic stent, which currently remains in the liver, and bile cytology. In addition, a liver biopsy was performed to diagnose the hepatic tumor in S7. Cholangiography from the plastic tube showed stenosis in the middle bile duct (Fig. 3a). Bile cytology demonstrated malignant cells that were suggestive of adenocarcinoma (Fig. 3b). There was an insufficient amount of specimen to conduct immunohistochemical staining and genetic testing. Therefore, it was difficult to discriminate between metastatic cholangiocarcinoma of gastric cancer and primary cholangiocarcinoma only by bile cytology. However, because there were no lymph node metastases or dissemination around the bile duct, and the tumor was expressed as a purely biliary intraductal mass by the image findings, we diagnosed the patient with primary cholangiocarcinoma rather than metastatic cholangiocarcinoma.

However, tissue similar to gastric cancer, which was resected at 81 years of age, was collected during a liver biopsy. Immunostaining of the biopsy specimens showed liver metastasis from gastric cancer. Therefore, the patient was diagnosed with primary bile duct cancer and liver metastasis 

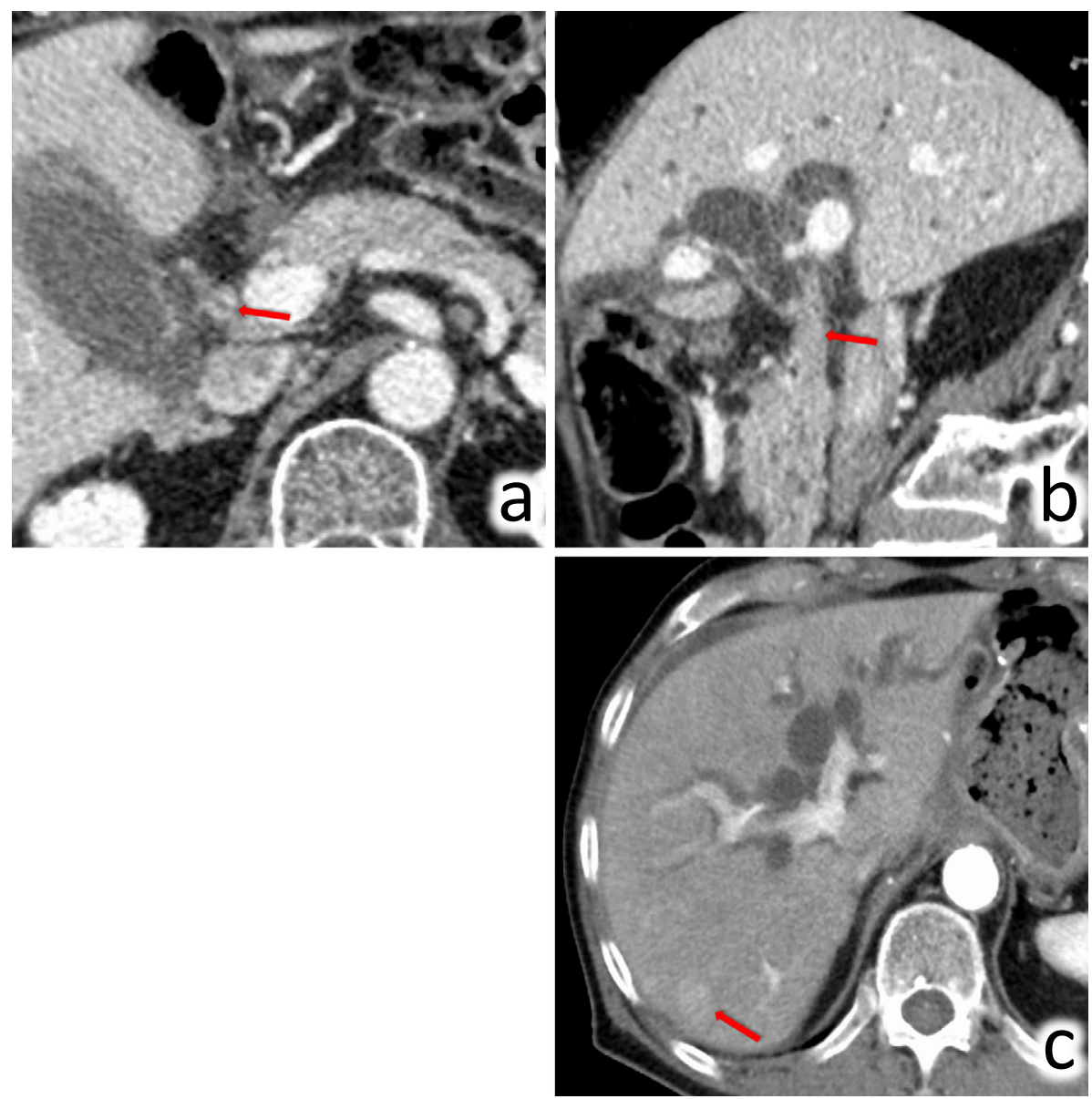

Figure 2. Abdominal CT on admission. a, b: Bile duct wall thickening and tumor formation were observed in the middle bile duct (red arrow). c: A liver tumor with contrast effect in the arterial phase was detected in liver segment $\mathrm{S} 7$ (red arrow).

from gastric cancer. His jaundice was improved after PTCD, and the plastic stent was replaced with a metallic stent for internal drainage at a later date. Although the patient was elderly, he received chemotherapy of tegafur/gimeracil/ oteracil potassium capsules (S-1). Finally, the patient was discharged 48 days after hospital admission (Fig. 4).

\section{Discussion}

CCS is a rare, nonfamilial disorder of unknown etiology associated with alopecia, cutaneous hyperpigmentation, gastrointestinal polyposis, onychodystrophy, diarrhea, weight loss, and abdominal pain (1). In 1995, CCS was divided into five groups according to the predominant symptom (7): Type 1: diarrhea; Type 2: dysgeusia; Type 3: abnormal sensation in the mouth with thirst; Type 4: abdominal symptoms other than diarrhea; and Type 5: alopecia. All patients must have gastrointestinal polyposis and hyperpigmentation. According to these findings, the present patient was presumed to be Type 1. Recent literature recommends combination therapy based on parenteral nutrition, antibiotics, and corticosteroids (8). In the present case, the symptoms of alopecia, hyperpigmentation, diarrhea, and gastrointestinal polyposis were improved by prednisolone.
The histological specimens from the stomach and small and large intestines showed typical features of benign juvenile-like or inflammatory polyps. The question of whether the juvenile-like or inflammatory polyps in CCS possess malignant potential remains controversial (9). However, reports of malignant diseases, particularly gastric and colorectal cancer, merged with CCS have recently increased (4-6). There are case reports to suggest that both typical adenomatous and serrated polyp pathways may be involved, and the overall risk of gastric and colorectal cancer is suggested to be as high as 5-25\% (5, 9-15). It is evident that CCS patients have a high risk of gastric and colorectal cancer. It is possible that the chronic generalized mucosal inflammation in CCS increases neoplastic transformation, similar to the inflammation-induced mutagenesis of idiopathic inflammatory bowel disease $(14,16,17)$. However, how these polyps are associated with cancer formation remains unclear. There are reports that carcinoma of organs other than the stomach or colon occurs in CCS patients. The following cases have been reported: CCS associated with esophageal, gastric and lung cancer (18); CCS associated with primary esophageal and gastric cancers (19); and CCS complicated with cholangiocarcinoma (20). In the present case, gastric and colon cancers were detected during remis- 

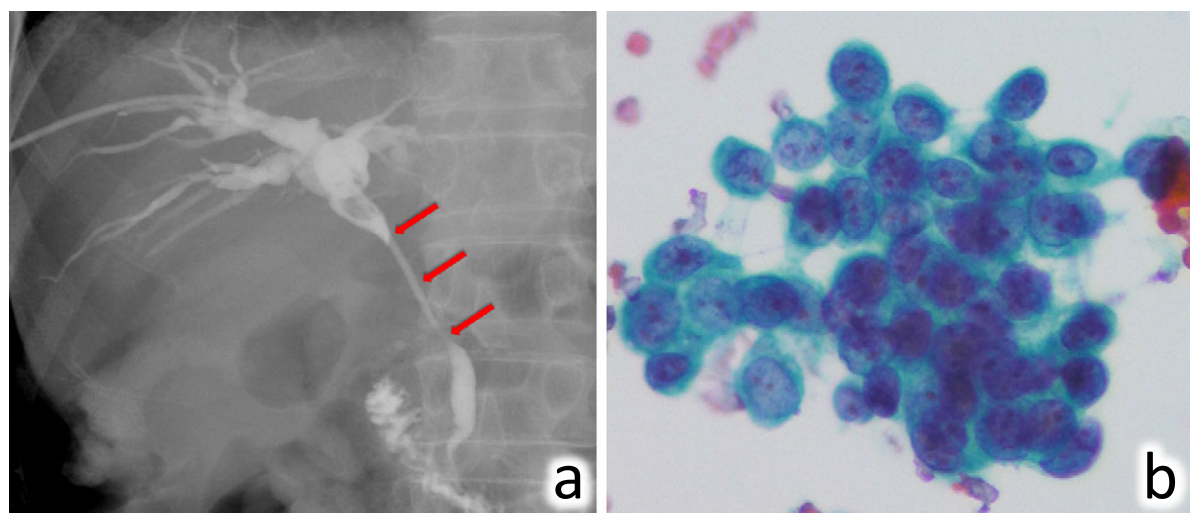

Figure 3. a: Cholangiography from the plastic tube showed stenosis in the middle bile duct (red arrows) after PTCD. b: Bile cytology using Papanicolaou stain diagnosed malignant cells that were suggestive of adenocarcinoma.

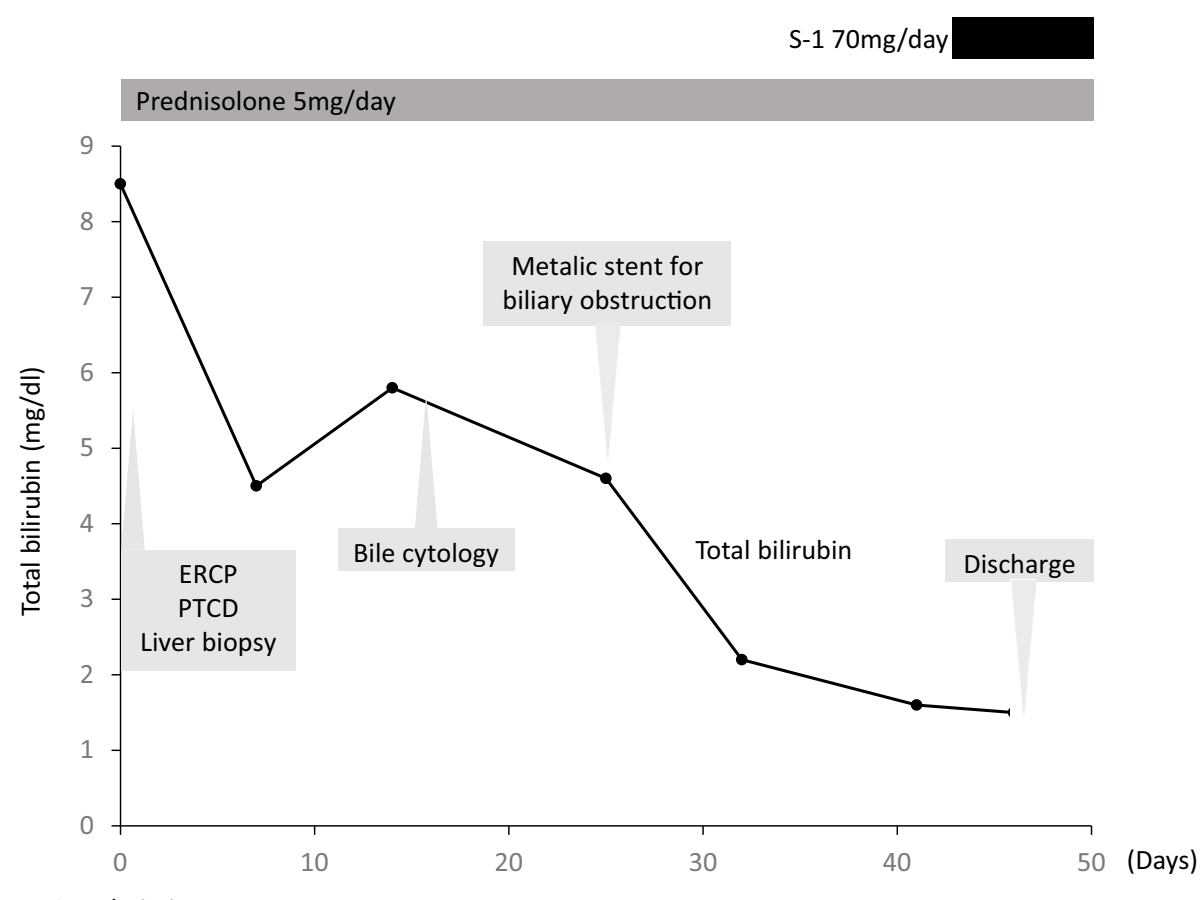

On admission

Figure 4. Clinical course of the patient. The solid line indicates total bilirubin levels.

sion of CCS when multiple polyps had disappeared. Nevertheless, cholangiocarcinoma was complicated by CCS after surgery for gastric and colon cancers. Therefore, the patient was suspected to have primary cholangiocarcinoma rather than metastatic cholangiocarcinoma according to the image findings (21). However, it is unknown whether the same mechanism for the onset of gastrointestinal carcinoma is associated with the occurrence of cholangiocarcinoma in CCS. Our patient was only evaluated by bile cytology. A bile duct biopsy might have been helpful in understanding the background cancer and determining whether there were juvenilelike or inflammatory changes.

The morbidity of colorectal cancer, gastric cancer, and cholangiocarcinoma increases as the patient ages according to a Japanese cohort study (22). Therefore, these cancers may be complicated by age in an elderly patient. However, when we take into account the number of CCS patients, the morbidity of cholangiocarcinoma or other cancers in CCS patients may be higher than that in the general population. Although this case was rare, careful attention is necessary for gastrointestinal carcinoma and cholangiocarcinoma or cancer of other organs during the follow-up of patients with CCS.

In conclusion, we herein described a case of CCS complicated with cholangiocarcinoma who was previously treated for gastric and colon cancers. Patients with CCS might develop carcinoma in organs other than those in the gastrointestinal tract.

The authors state that they have no Conflict of Interest (COI). 


\section{References}

1. Cronkhite LW, Canada WJ. Generalized gastrointestinal polyposis: an unusual syndrome of polyposis, pigmentation, alopecia and onychotrophia. N Engl J Med 252: 1011-1015, 1955.

2. Kopáčová M, Urban O, Cyrany J, et al. Cronkhite-Canada syndrome: review of the literature. Gastroenterol Res Pract 2013: 856873, 2013.

3. Devulder F, Bouché O, Diebold MD, et al. Cronkhite-Canada syndrome: a new French case. Gastroenterol Clin Biol 23: 407-408, 1999 (in French).

4. Isobe T, Kobayashi T, Hashimoto K, et al. Cronkhite-Canada syndrome complicated with multiple gastric cancers and multiple colon adenomas. Am J Case Rep 14: 120-128, 2013.

5. Egawa T, Kubota T, Otani Y, et al. Surgically treated CronkhiteCanada syndrome associated with gastric cancer. Gastric Cancer 3: 156-160, 2000.

6. Karasawa H, Miura K, Ishida K, et al. Cronkhite-Canada syndrome complicated with huge intramucosal gastric cancer. Gastric Cancer 12: 113-117, 2009.

7. Goto A. Cronkhite-Canada syndrome: epidemiological study of 110 cases reported in Japan. Nihon Geka Hokan (Arch Jpn Chir) 64: 3-14, 1995 (in Japanese).

8. Kao KT, Patel JK, Pampati V. Cronkhite-Canada syndrome: a case report and review of literature. Gastroenterology Res Pract 2009: 619378, 2009.

9. Watanabe C, Komoto S, Tomita K. Endoscopic and clinical evaluation of treatment and prognosis of Cronkhite-Canada syndrome: a Japanese nationwide survey. J Gastroenterol (in press).

10. Nagata J, Kijima H, Hasumi K, et al. Adenocarcinoma and multiple adenomas of the large intestine, associated with CronkhiteCanada syndrome. Dig Liver Dis 35: 434-438, 2003.

11. Katayama Y, Kimura M, Konn M. Cronkhite-Canada syndrome associated with a rectal cancer and adenomatous changes in colonic polyps. Am J Surg Pathol 9: 65-71, 1985.
12. Malhotra R, Sheffield A. Cronkhite-Canada syndrome associated with colon carcinoma and adenomatous changes in C-C polyps. Am J Gastroenterol 83: 772-776, 1988.

13. Jain A, Nanda S, Chakraborty $P$, et al. Cronkhite-Canada syndrome with adenomatous and carcinomatous transformation of colonic polyp. Indian J Gastroenterol 22: 189-190, 2003.

14. Yashiro M, Kobayashi H, Kubo N, Nishiguchi Y, Wakasa K, Hirakawa K. Cronkhite-Canada syndrome containing colon cancer and serrated adenoma lesions. Digestion 69: 57-62, 2004.

15. Sweetser S, Ahlquist DA, Osborn NK, et al. Clinicopathologic features and treatment outcomes in Cronkhite-Canada syndrome: support for autoimmunity. Dig Dis Sci 57: 496-502, 2012.

16. Seshadri D, Karagiorgos N, Hyser MJ. A case of CronkhiteCanada syndrome and a review of gastrointestinal polyposis syndromes. Gastroenterol Hepatol (NY) 8: 197-201, 2012.

17. Sweetser S, Boardman LA. Cronkhite-Canada syndrome: an acquired condition of gastrointestinal polyposis and dermatologic abnormalities. Gastroenterol Hepatol 8: 201-203, 2012.

18. Kaneko Y, Kato H, Tachimori $\mathrm{Y}$, et al. Triple carcinomas in Cronkhite-Canada syndrome. Jpn J Clin Oncol 21: 194-202, 1991.

19. Ito $M$, Matsumoto $S$, Takayama $T$, et al. Cronkhite-Canada syndrome associated with esophageal and gastric cancers: report of a case. Surg Today 45: 777-782, 2015.

20. Hirasaki S, Tanimizu M, Moriwaki T, Kajiwara T, Nishina T, Hyodo I. A case of Cronkhite-Canada syndrome associated with cholangiocellular carcinoma. Nihon Shokakibyo Gakkai Zasshi (Japanese Journal of Gastroenterology) 102: 583-588, 2005 (in Japanese).

21. Lee YJ, Kim SH, Lee JY, et al. Differential CT features of intraductal biliary metastasis and double primary intraductal polypoid cholangiocarcinoma in patients with a history of extrabiliary malignancy. AJR Am J Roentgenol 193: 1061-1069, 2009.

22. National Cancer Center, Cancer Statistics in Japan [Internet]. [cited 2015 Nov. 1]. Available from: http://ganjoho.jp/reg_stat/inde x.html (in Japanese).

(C) 2016 The Japanese Society of Internal Medicine http://www.naika.or.jp/imonline/index.html 